\title{
Improvement of existing coal fired thermal power plants performance by control systems modifications
}

\author{
Robert Mikulandrić $^{\mathrm{a}, *}$, Dražen Lončar ${ }^{\mathrm{a}}$, Dejan Cvetinović ${ }^{\mathrm{b}}$, Gabriel Spiridon $^{\mathrm{c}}$ \\ ${ }^{a}$ Department of Energy, Power Engineering and Ecology, Faculty of Mechanical Engineering and Naval Architecture, University of Zagreb, \\ No.5 Ivana Lučića, 10000 Zagreb, Croatia \\ ${ }^{\mathrm{b}}$ Laboratory for Thermal Engineering and Energy, Institute of Nuclear Science "Vinča”, University of Belgrade, No. 12 Mike Petrovića Alasa, \\ 11351 Vinča, Belgrade, Serbia \\ ${ }^{\mathrm{c}}$ RED Institute for Scientific Research and Technological Engineering for Automation - IPA SA, No. 69 Calea Floreasca Street, 014459 Bucharest, \\ Romania
}

\section{A R T I C L E I N F O}

\section{Article history:}

Received 29 August 2012

Received in revised form

4 February 2013

Accepted 9 February 2013

Available online 16 March 2013

\section{Keywords:}

Coal combustion modelling

Coal combustion optimisation

Artificial intelligence systems

West Balkan power sector

\begin{abstract}
A B S T R A C T
This paper presents possibilities of implementation of advanced combustion control concepts in selected Western Balkan thermal power plant, and particularly those based on artificial intelligence as part of primary measures for nitrogen oxide reduction in order to optimise combustion and to increase plant efficiency. Both considered goals comply with environmental quality standards prescribed in large combustion plant directive. Due to specific characterisation of Western Balkan power sector these goals should be reached by low cost and easily implementable solution. Advanced self-learning controller has been developed and the effects of advanced control concept on combustion process have been analysed using artificial neural-network based parameter prediction model.
\end{abstract}

다 2013 Elsevier Ltd. All rights reserved.

\section{Introduction}

Emission mitigation and thermal power plant (TPP) efficiency improvement are particularly important projects in terms of reducing climate changes [1]. The necessity for such projects is formulated in the Kyoto Protocol and EU directives. Environmental related issues are specially emphasised for West Balkan region where most of power is generated by coal fired thermal power plants. Power sector in Western Balkan region is characterised by low thermal power plant efficiency, high $\mathrm{NO}_{x}, \mathrm{SO}_{x}$ and $\mathrm{CO}_{2}$ emissions and low quality of coal that is used for power generation. Limited investment potential impose the need for easily implementable, low cost solutions that encounters emissions related issues and raises thermal power plant efficiency. Usage of advanced control technology in power generation represents potential for improvement in the terms of processes optimisation, emissions reduction and efficiency improvement. Their impact depends on technical characteristics and status of existing instrumentation and control systems as well as on design characteristics and actual conditions of installed plant components.

\footnotetext{
* Corresponding author.

E-mail addresses: robert.mikulandric@fsb.hr (R. Mikulandrić), dloncar@fsb.hr (D. Lončar), deki@vinca.rs (D. Cvetinović).
}

During combustion process in thermal power plant nitrogen oxides $\left(\mathrm{NO}_{x}\right)$ are formatted due to nitrogen bounded in fuel (fuel $\mathrm{NO}_{x}$ ), high-temperature combustion and residence time of nitrogen molecules at high temperatures (thermal $\mathrm{NO}_{x}$ ) and reaction of atmospheric nitrogen during combustion (prompt $\mathrm{NO}_{x}$ ). One solution for emission mitigation problem is implementation of secondary measures technology in existing thermal power plants (selective catalytic reduction, selective non-catalytic reduction etc.) [2]. Another solution is getting primary measures closer to the power plant processes limits using advanced techniques regarding power, temperature and combustion control as one of combustion treatments. These measures optimise fuel and air distribution to suppress $\mathrm{NO}_{x}$ formation and they can be very useful and cost effective [3]. Combustion control technology is one of the most cost-effective measures in $\mathrm{NO}_{x}$ emissions reduction [4]. Although effective in terms of emission reduction, these measures could reduce thermal power plan efficiency due to increase of auxiliary power consumption. Design and simulation of combustion models by means of mathematical, physical and chemical analysis often require extensive computational resources which is usually impractical for on-line control [5].

Artificial intelligence systems (AIS) are widely accepted as a technology offering an alternative way to tackle complex problems. Their general goal is to devise models that are analogous to human- 
brain-like models or biologically inspired networks. They can learn from examples, they are fault tolerant (limited by complexity of analysed system) in the sense that they are able to handle noisy and incomplete data, they are able to deal with non-linear problems, and once trained, they can perform prediction and generalization at high speed. They have been used in diverse applications in control [6], robotics [7], pattern recognition [8], prediction [9-13], medicine [14,15], power systems, monitoring [16,17], manufacturing [18], optimization [19,20], signal processing [21], and social/psychological sciences [22]. Advanced control technologies for improving system operability and environment maintainability based on artificial-intelligence (AI) seems to be promising approach for modelling $[23,24]$ and controlling large and nonlinear power generation processes. They are particularly useful in system modelling such as in implementing complex mappings [25] and system identification [26].

Artificial neural networks (ANN) and neuro-fuzzy models are currently the most researched approaches to $\mathrm{NO}_{x}$ emission modelling [27]. They have proved their effectiveness on emissions prediction and control [28]. Artificial neural networks can achieve good $\mathrm{NO}_{x}$ emission prediction effects under various operating conditions [29]. For coal combustion modelling, support vector regression approach [30] and generic algorithm approach [30] are used, where unknown parameters act as random variables with a known prior probability distribution. The process identification starts with process observation (measured data). Using measured data (thermal power plant database), artificial neural network combustion models can be created. ANN models are more useful than physical models as these can be trained occasionally with latest data, taking care of the degradation of the plant [31]. An artificial neural network visual model of the circulating fluidised bed process and emissions can be also efficient in coal combustion modelling.

In the recent time, Evolutional Algorithms (EAs) are used as optimisation techniques which simulate biological systems for optimisation problems. Such algorithms have been developed to solve large-scale optimisation problems, for which traditional mathematical techniques may fail. The typical EAs include genetic algorithm (GA), particle swarm optimization (PSO) and ant colony systems (ACO). The ant colony optimization algorithm draws its inspiration from the behaviour of real ants as they move from their nest towards a food source, while PSO is inspired by social behaviour of bird flocking. Among these optimization methods, only GA is used by few studies to optimize operational conditions of the boiler for $\mathrm{NO}_{x}$ emissions abatement and for efficiency maximisation [32,33] while optimization technology based on ACO and PSO [34] systems are widely used in many science and engineering fields [5].

\section{Artificial intelligence control systems}

If the standard controller is replaced with neural networks or fuzzy inference systems, then the system is called neural network or fuzzy control system. Neuro-fuzzy control refers to the design methods for fuzzy logic controllers that employ neural network techniques which have properties such as learning ability, parallel operation, structured knowledge representation and better integration with other control design methods.

Combustion control in TPP is mostly conducted through fuel and air flow control. Conventional air flow control in coal TPPs burners consist of cascade of PI controllers, described in Ref. [35]. Values of total, secondary and tertiary air flows in air flow control are often in non-optimal range due to linear approximation of required air flows regarding input parameters. Additional/correction coefficients could be implemented into conventional air flow control in order to give more realistic input signals and to improve overall process control. Potential locations of providing correction coefficients based on AIS technology into conventional TPP air flow control are shown in Fig. 1.

ANN's are widely used tool in area of Power System Control (PSC). They have been used and tested in economic load dispatch, loss reduction, frequency control, load forecasting, power system analysis, fault detection and diagnosis and security assessment and

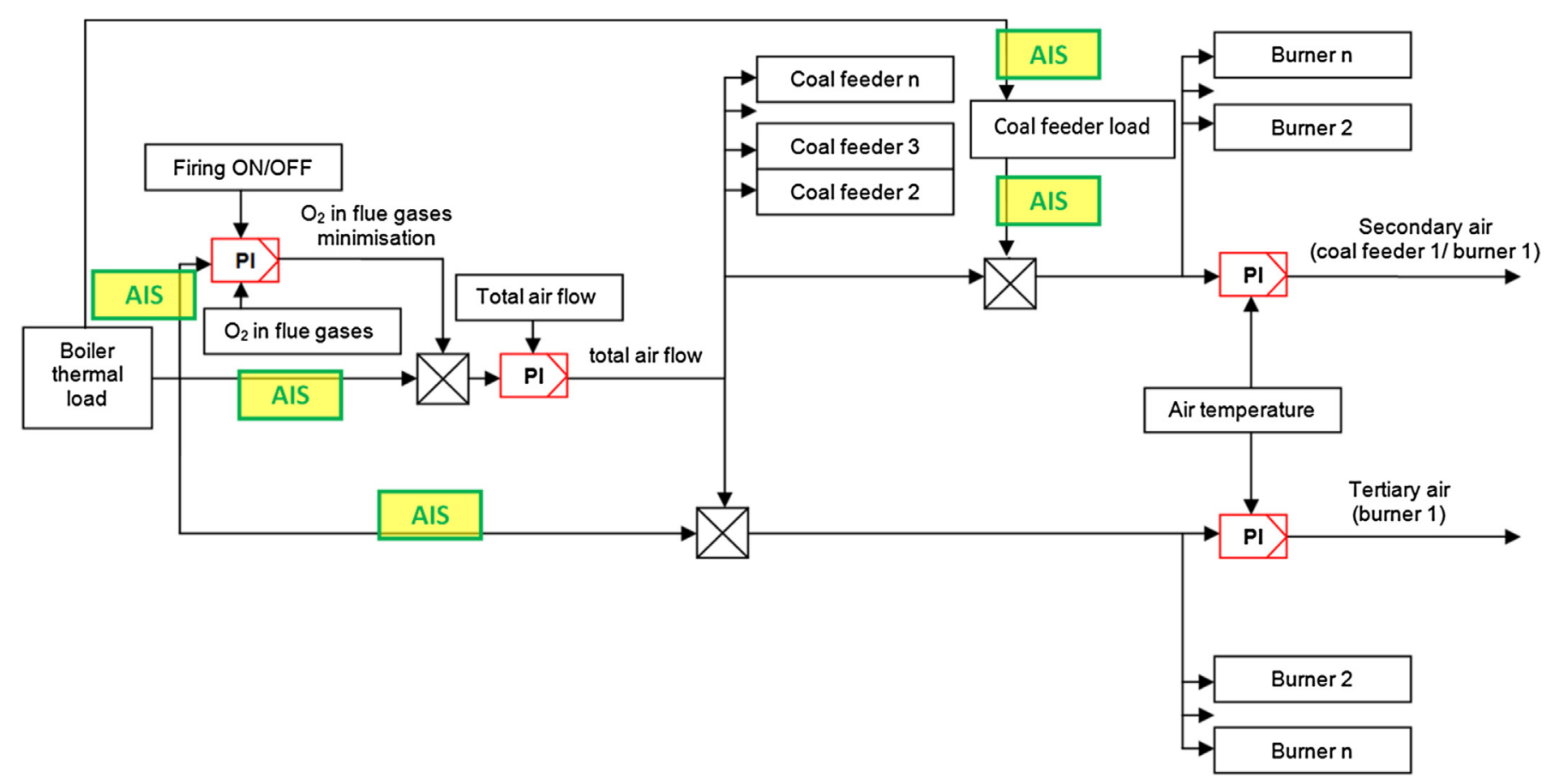

Fig. 1. Potential places for Artificial Intelligence Systems introduction to conventional TPP air flow control [35]. 
enhancement. In economic load dispatch and loss reduction control ANNs have been used to solve fuel constrained economic emission load dispatch problems of thermal generating units [36] and to plan the optimal dispatch of each generating unit [37]. For frequency control, ANN is used to improve power system dynamic performance over a wide range of operating conditions [38]. ANN system have been extensively used for load forecasting [39], energy demand forecasting [10], long-term energy consumption prediction [11] etc. In fault detection and diagnostic technology, ANN can be created as an online system for condition monitoring and diagnosis of a combined heat and power plant [13] or they can be used for transient stability analysis and preventive control of electric power systems [40,41].

As stated in Ref. [42], ANN are still facing some problems such as database size and partitioning. Data that is used for training should be sufficiently large to cover parameter variation in problem domain. Before the data can be used for training it should be properly pre-processed (including noise removal, data transformation etc.). Balancing data is also needed to prevent the network from being biased to the over-represented classes. In some cases, to expand the size of database, data enrichment is needed. Normalisation (scaling) of data is essential to prevent larger numbers to override smaller ones and to prevent premature saturation of hidden nodes. Appropriate convergence criteria and number of training cycles must be applied for training procedure. Determination of appropriate number of hidden layers and number of hidden nodes in each layer is one of the most critical tasks in ANN design. In most prediction models, one hidden layer is sufficient for modelling. Generally, ANN limitations include lack of clear rules or fixed guidelines for optimal ANN model design, lack of physical concepts and relations and lack of quality and quantity of the training data.

For emission control, artificial intelligence self-learning controllers have been successfully implemented on dozen large scale power plants in Europe, USA and Asia. They have shown their effectiveness on $\mathrm{CO}$ and $\mathrm{NO}_{x}$ emissions minimisation up to 40\% [43] and power plant performance improvement. In similar artificial intelligence controller cases, combustion optimisation adjusts the fuel and air biases within the furnace to improve the combustion process, thereby controlling emissions. Successful $\mathrm{NO}_{x}$ formation reduction can be achieved by changing load dependant burners input variables (secondary and tertiary air on burner layers) [44]. The $\mathrm{NO}_{x}-\mathrm{CO}$ trade-off is looked after by adjusting the air dampers, mainly along the "vertical" boiler axis, adjusting primary, secondary and, if available, tertiary air in conjunction with the excess oxygen control. This model-based boiler optimisation system predicts future outputs based on the past and calculated future values of the input variables [33].

Negative effect of $\mathrm{NO}_{x}$ control on power generation efficiency consists mainly of an increase of auxiliary power consumption for fans and pumps to drive the pollution control devices (mostly related with secondary $\mathrm{NO}_{x}$ reduction measures), etc. The effect on net energy efficiency is up to $2 \%$ for coal-fired power plants (wet scrubber, SCR and combustion modification). In some cases there is also an effect on gross efficiency of at most $1 \%$ due to loss of boiler efficiency or additional fuel consumption [45].

In other "state of art" cases, $\mathrm{CO}$ values are estimated in dependence of numerically generated optical analysis. These estimated $\mathrm{CO}$ are further used to create more stable and faster closed loop control of air flow [46]. With the help of the measured velocity distribution not only the coal mass flow can be calculated but also the mass flow of the gas (air) flow since the smallest particles have a very high level of entrainment and follow the transporting gas with little slip. Thus, the air-fuel ratio can be directly determined [47]. Most of these low-cost emission and efficiency control systems have been successfully demonstrated and employed in several plants, but they are still facing difficulties regarding maintenance during operating life of the plant and sensitivity to the type of coal used and problems with auxiliary material (ammonia, urea, limestone, gypsum) [48].

In this work, methodology for development of Artificial Intelligence System based combustion control and optimisation system is divided into two stages. In the first stage, the relation between $\mathrm{NO}_{x}$ emissions and various operational parameters of the boiler will be modelled. Afterwards, operational parameters for low $\mathrm{NO}_{x}$ combustion are optimised. Optimisation is devised through selflearning optimisation algorithms that are used to find optimal set of process parameter during power plant operation in order to minimise $\mathrm{NO}_{x}$ formation and increase efficiency. Optimal set of process parameters will be used to define correction factors for conventional air flow control. Effect of correction factor implementation on combustion process will be analysed through simulation of combustion process. Process simulation will be based on combustion process parameter and emission prediction model.

\section{Process parameter and emission prediction modelling}

For process parameter and emission prediction modelling, model derived from previous work described in Ref. [35] has been used. Data for learning algorithm were extracted from minute based field measurements at the 650 MWe coal fired thermal power plant. Data was collected in several measuring campaigns comprising following measurements/analyses: coal mass flow to the mill at the conveyer belt and coal feeder; grinding fineness for each dust line and mill; gas phase velocity in all dust lines, temperature in all dust lines; pressure drop in all dust lines; laboratory analyses of raw lignite (heating value, moisture and ash content); laboratory analyses of lignite dust (fineness of grinding and moisture content); fuel (coal + heavy oil), burning air and flue gases flows; flue gases analyses at adequate sampling points $\mathrm{O}_{2}, \mathrm{CO}_{2}, \mathrm{CO}$, $\mathrm{NO}_{2 \text { eq }}$; temperatures of the thermical agents: flue gases (at the end of the combustion chamber and in the gas sampling points), feed water, primary and secondary steam and air temperature after air preheater. The respective unit operating data were recorded at the unit control system during the test. All data were recorded on a minute base in a correspondence with relevant international standards for this type of measurements.

The uncertainty of an overall test results is dependant upon the collective influence of the uncertainties of the data used in determining the test result and can be calculated according to the American National Standard ANSI/ASME PTC 6 report. Uncertainties can be divided in several groups regarding measurement physical quantity (electrical power, throttle flow, reheat flow, throttle pressure and throttle temperature). Each measurement has different uncertainty ratio and different effect on the total heat rate. The averaged total uncertainty of the measurements used in this research can be calculated at the level of $\pm 1.3 \%$ for used measurement techniques and sophisticated measurement equipment that was used in data collection.

Data preprocessing has been carried out regarding methodology described in Ref. [35] and erroneous data (called "outliers") has been removed from neuro-fuzzy training data. For devising process parameter and emission prediction model, Mamdani model [49] with Gauss membership functions [50] has been used. Prediction model has been devised in MATLAB ${ }^{\circledR}$ programming tool. ANFIS process parameter prediction model have shown good correlation with real process parameters [35]. Some modelling results are showed in Figs. 2 and 3.

Air flow on high TPP loads is high due to nature of combustion process. Increase of the air flow on lower loads results in higher 


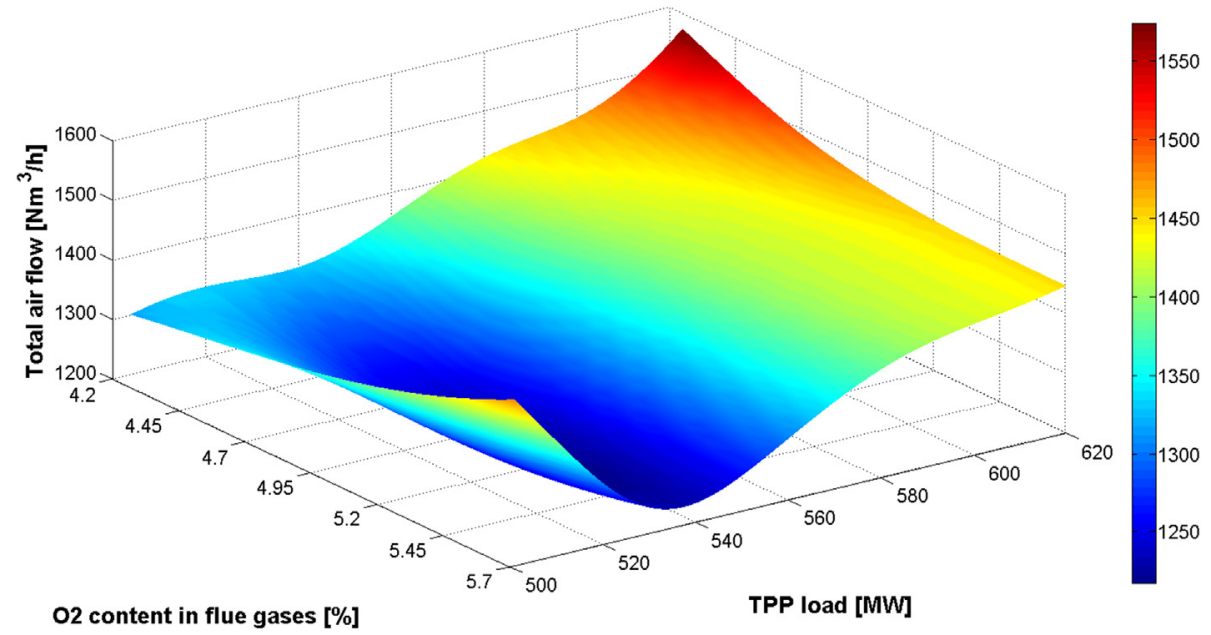

Fig. 2. Calculated approximations of total air flow in dependence of Unit load and $\mathrm{O}_{2}$ content in flue gasses as input values [35].

content of oxygen in flue gasses (Fig. 2). Generally, with unit load increase, $\mathrm{NO}_{x}$ emission values declines. On the same TPP output, with air flow increase, the $\mathrm{NO}_{x}$ emission rises (Fig. 3).

After introducing approximation models, actual control maps for combustion control have been generated (Fig. 4).

\section{System optimisation method}

Sets of different measurements from coal fired TPP unit (in further text Unit) have been used for creating a self-learning controller that allows on-line plant process optimisation. $\mathrm{NO}_{x}$ emissions and all related parameters in operating regimes have been collected in correlation with Unit output. For single Unit output $(\mathrm{P})$ value and corresponding coal lower heating value (LHV), $\mathrm{NO}_{x}$ values data from previous operational regimes are collected and compared to find optimal process parameter values settings (burner load, secondary and tertiary air flows...) where lowest $\mathrm{NO}_{x}$ emission or/and highest efficiency occurs. Because optimal process parameters values settings have been found from already existing database, therefore is also a possibility to find "new" optimal process parameters values settings during power plant operation (from operating regime that has not already been in database). This can be done by process parameters variation or simply during thermal power plant operation. When a better process parameter settings are found (from the standpoint of $\mathrm{NO}_{x}$ emission or/and efficiency), than algorithm automatically sets these new settings as optimal. This process can be called "controller training". Fig. 5 shows flow chart for self-learning controller utilisation. Optimisation method has been conducted in MATLAB ${ }^{\circledR}$ programming tool. Coal heating value and composition is calculated regarding specifications given by coal provider.

Fuel heating value has been taken as constant (based on main guarantied design parameters of the coal). The lower heat capacity value of the fuel is $6.699 \mathrm{MJ} / \mathrm{kg}$, the moisture content is $47.8 \%$, the ash content is $19 \%$ and the content of sulphur is $0.5 \%$. In the real power plant operation this will not be the case. Fuel with different composition (heating value, moisture composition etc.) is used for combustion process. Lack of coal quality homogenization can cause problems from the point of combustion optimisation. Only small divergence of the coal quality parameters (within the range of $\pm 5 \%$ ) enables the optimization of the combustion process in the furnaces. However, due to the lack of homogenization, i.e. the equalization of the coal quality, the lower heat capacity of the coal supplied to the unit can range from 5 to $9 \mathrm{MJ} / \mathrm{kg}$.

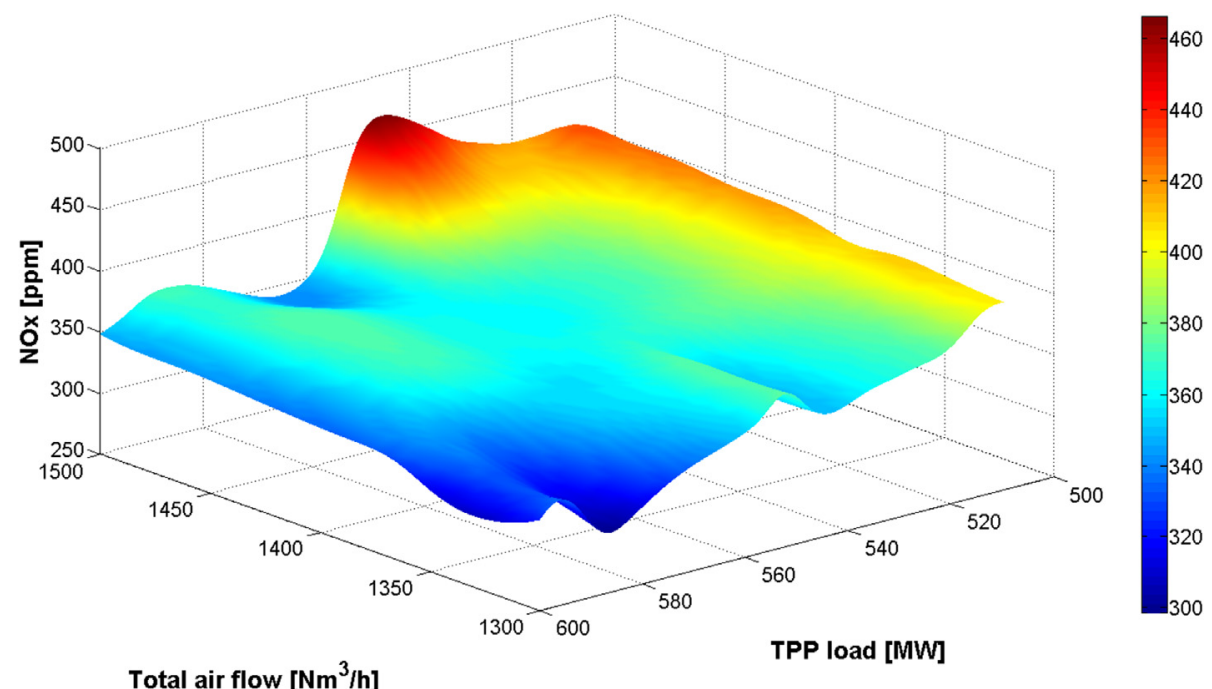

Total air flow $\left[\mathrm{Nm}^{3} / \mathrm{h}\right]$

Fig. 3. $\mathrm{NO}_{x}$ emission approximations in dependence of TPP load and total air flow [35]. 


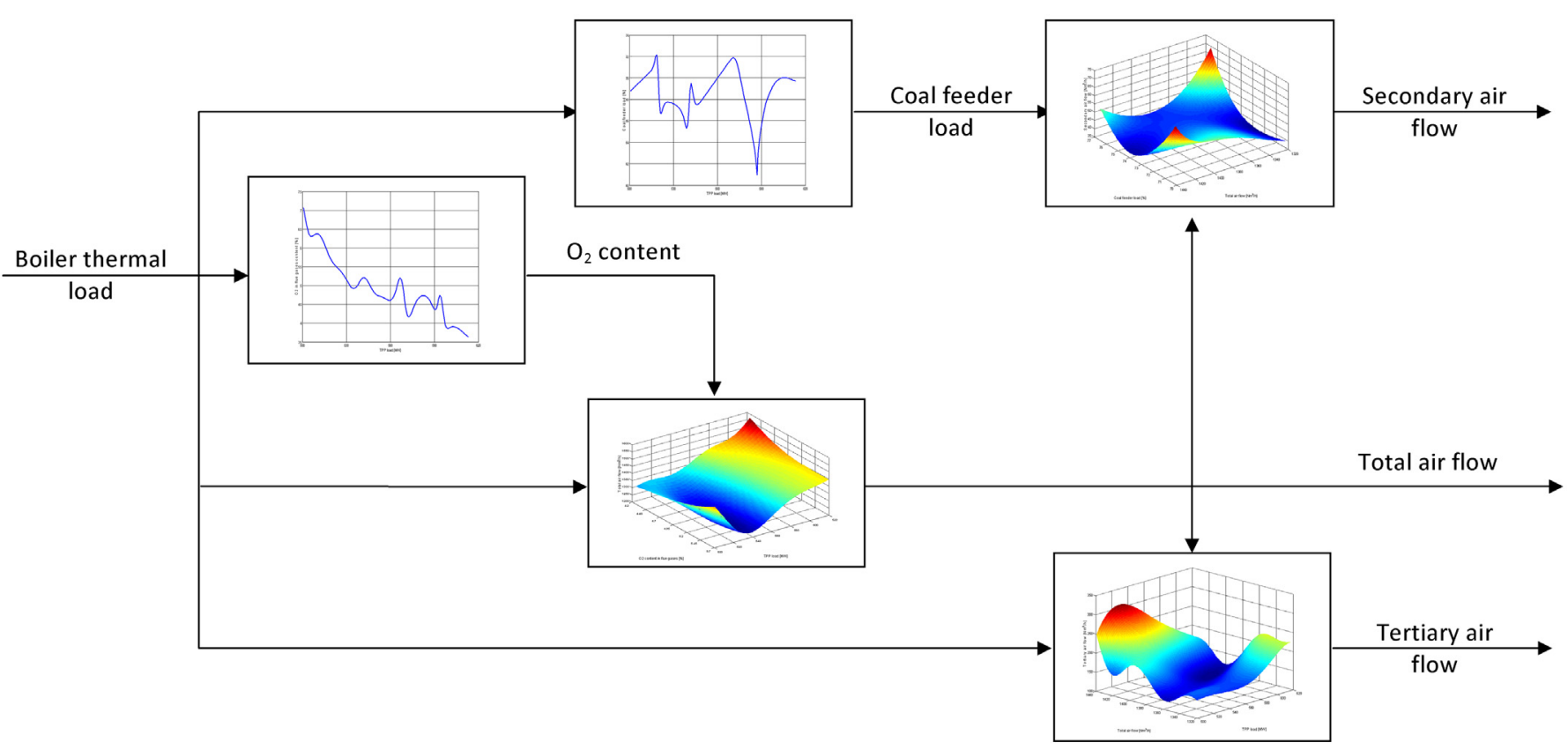

Fig. 4. Actual control maps for air flow control.

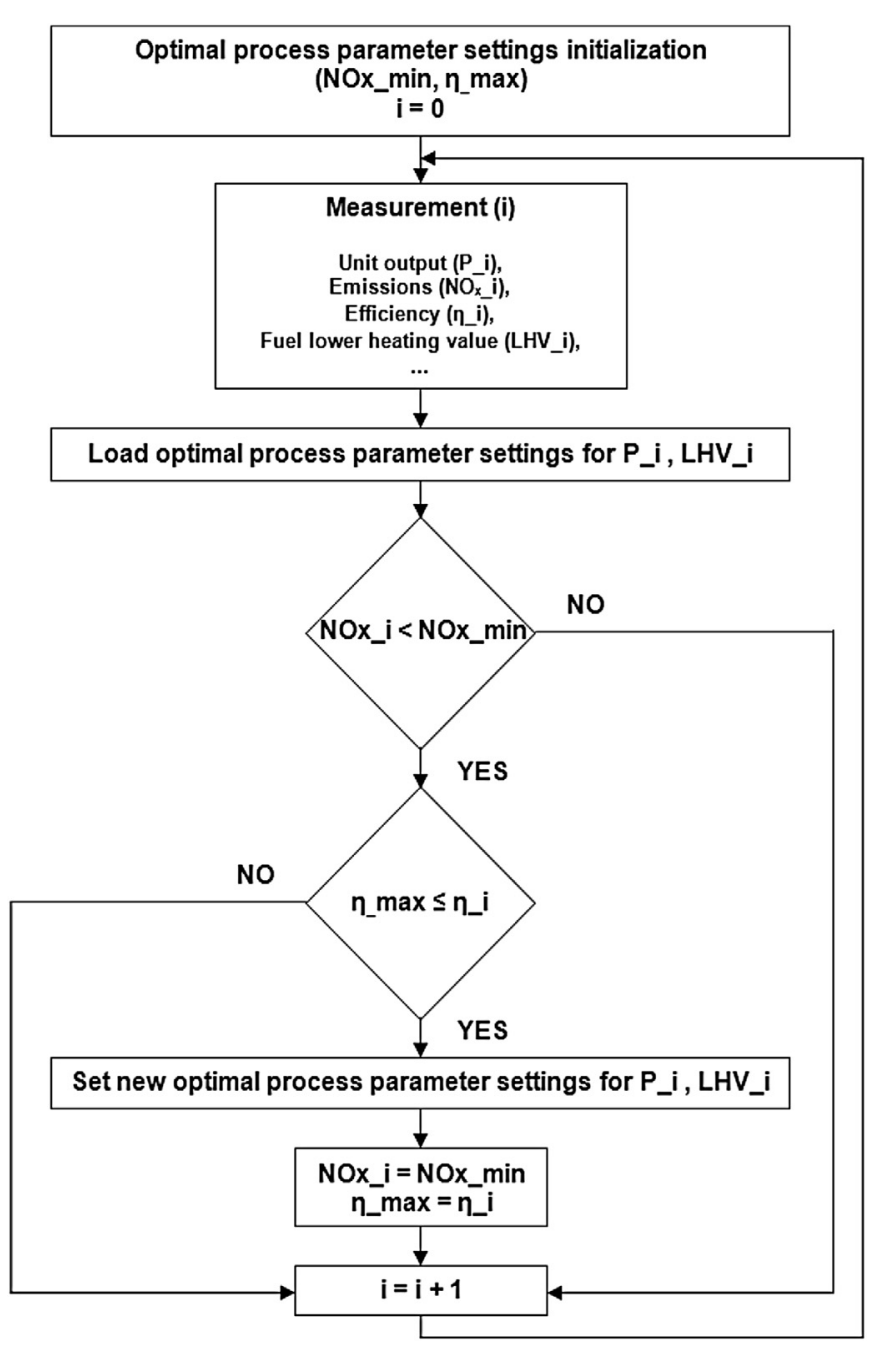

Fig. 5. Flow chart for self-learning controller utilisation.
As mentioned before, for creating a self-learning controller that enables on-line plant process optimisation all related operating parameters from Unit's operation are collected and compared. The operating regimes with minimum $\mathrm{NO}_{x}$ emissions (red squares, in web version) regarding rated output (blue squares, in web version) are shown on Fig. 6. From these operating regimes, all operating parameter data settings have been extrapolated. These operating settings will be used as reference to create load depending correction coefficients in conventional control of total, secondary and tertiary air, as well as coal feeder load. Correction coefficients could be implemented in conventional air flow control scheme as showed in Fig. 1 and they will be limited to $\pm 10 \%$ in case of total air flow and $\pm 5 \%$ in case of secondary, tertiary air flow and coal feeder load. The reason behind this limitation is to preserve stable Unit operation controlled by implemented automation system.

\section{Results}

Results of advanced combustion optimisation implementation on combustion process have been analysed using developed process approximation model. Simulation of coal combustion process in dedicated TPP has been conducted in MATLAB/Simulink ${ }^{\circledR}$ simulation tool. Data from 24, 48, 72 and 96 Unit operation hours have been collected to train $24 \mathrm{~h}, 48 \mathrm{~h} 72 \mathrm{~h}$ and $96 \mathrm{~h}$ trained advanced, self-learning - artificially intelligence system based controller. Simulation results for $96 \mathrm{~h}$ power plant operation have been shown in Fig. 7.

With introduction of $24 \mathrm{~h}$ trained advanced controller (advanced optimisation), simulation shows that the $\mathrm{NO}_{x}$ formation rate could be reduced. Due to $\mathrm{NO}_{x}$ formation reduction, a total of $58.68 \mathrm{~g}$ of $\mathrm{NO}_{x}$ could be reduced during daily power plant operation (reduction of $0.42 \%$ ). After introduction of advanced controller that has been trained for $48 \mathrm{~h}, \mathrm{NO}_{x}$ emissions could be reduced for $127.15 \mathrm{~g}$ (0.91\%). Advanced controller that has been trained for $76 \mathrm{~h}$ has shown better results regarding $\mathrm{NO}_{x}$ reduction than 24 and $48 \mathrm{~h}$ trained advanced controller. $76 \mathrm{~h}$ trained advanced controller could reduce $\mathrm{NO}_{x}$ emissions for $135.53 \mathrm{~g}$ (0.97\%). Fig. 8 shows that maximum $\mathrm{NO}_{x}$ values could be reduced from $410 \mathrm{ppm}$ to $400 \mathrm{ppm}$ (2.44\%). $96 \mathrm{~h}$ trained advanced controller could reduce $\mathrm{NO}_{x}$ 

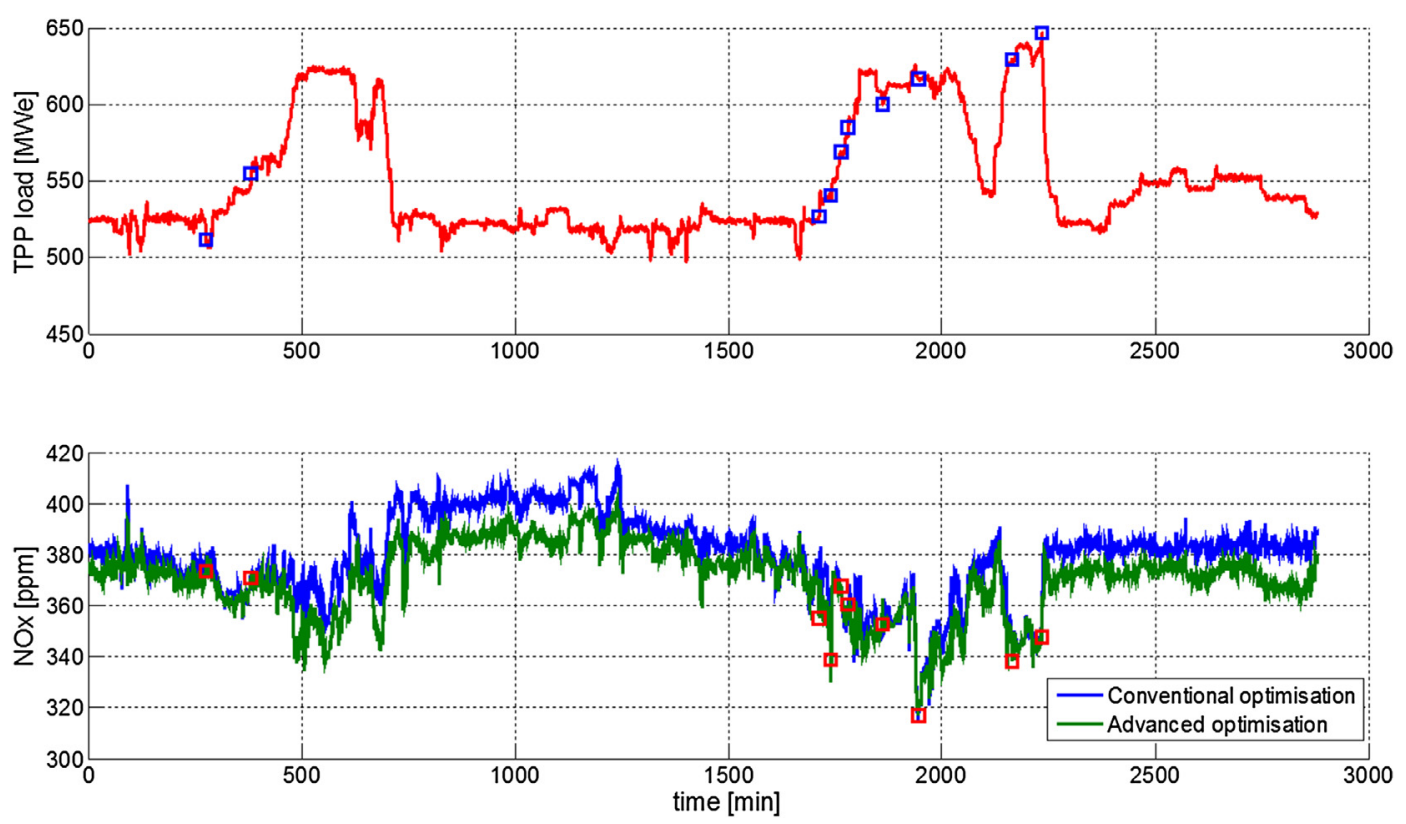

Fig. 6. Example of $48 \mathrm{~h}$ advanced controller training procedure.

emissions by $121.56 \mathrm{~g}(0.87 \%)$. Simulation generally shows that this type of advanced optimisation has potential in terms of $\mathrm{NO}_{x}$ minimisation and efficiency increase.

Due to methodology that has been implemented in this research, the accuracy of the determination of $\mathrm{NO}_{x}$ reduction and efficiency increase can be compared with the uncertainty of measurement test with addition of ANFIS prediction error values that can be found in Ref. [35]. Average determination error of $\mathrm{NO}_{x}$ reduction and efficiency increase is $4.25 \%$.

Over-learning of controller occurs when total reduction of $\mathrm{NO}_{x}$ emissions stops declining or even $\mathrm{NO}_{x}$ emissions starts to increase [51]. When this occurs, the $\mathrm{NO}_{x}$ values on the training set are driven to theirs minimum values, but when new data is presented to the model, the emissions become larger [52]. In our case, $\mathrm{NO}_{x}$ emission reduction after $48 \mathrm{~h}$ of training started to stagnate. After $72 \mathrm{~h}$ of training, $\mathrm{NO}_{x}$ emission reduction started to decline. This means that advanced controller is on the edge of over-learning phenomena and it is advisable not to go further with training process. Because of

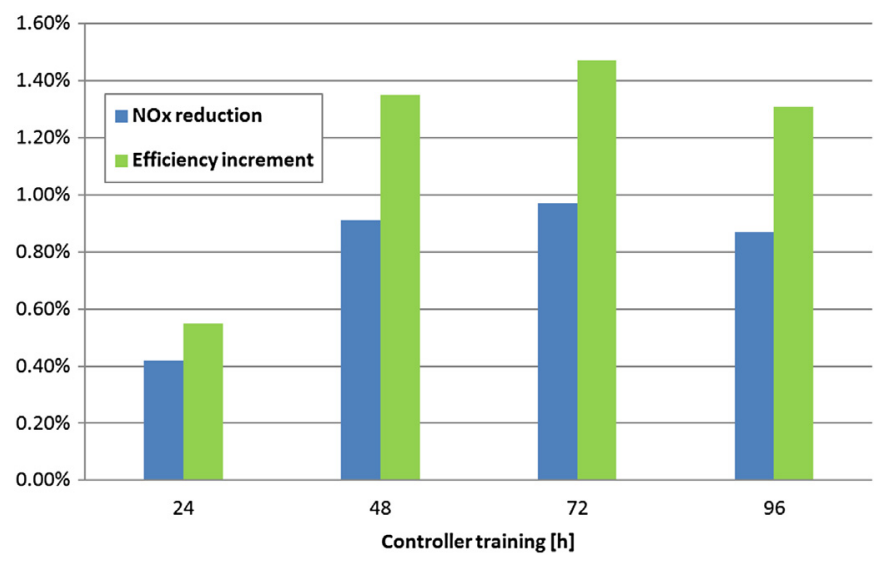

Fig. 7. Simulation results of average estimated $\mathrm{NO}_{x}$ reduction and efficiency increase during $96 \mathrm{~h}$ of power plant operation after advanced controller implementation (with correction coefficients). this reasons, the controller that has been trained for $72 \mathrm{~h}$ will be used for further optimisation analysis.

With advanced control concept (with correction coefficients) implementation into conventional air flow control scheme, the $\mathrm{NO}_{x}$ emissions have been reduced (Fig. 8 ). $\mathrm{NO}_{x}$ emissions are now raging from 310 to $400 \mathrm{ppm}$.

In analysed thermal power plant combustion is performed through 8 burners. Each burner is equipped with separately controlled coal feeder (CF). Results of Unit simulation show that advanced controller generally decreases coal feeder load. Less fuel is needed to generate the same output. Except fuel quantity, the distribution of coal through coal feeders has been changed. During $24 \mathrm{~h}$ TPP operation coal feeder loads on burners 1,5,6,7,8 have been decreased significantly while coal feeder loads on burners 3 and 4 have been decreased slightly (Fig. 9).

Simultaneously with burner load changes, primary air flow values are also changed. Although coal flow and air flow are in direct supervision of power plant automation system and they are controlled according to power demand, their values are often in non-optimal range because of linear approximation during calculation. By this we could expect some changes in air flow quantity and distribution in advanced control versus conventional air flow control. Primary air values are presented in Fig. 10. With burner load decrease, primary air flow also decreases. Even though, the air flow could be increased on some burners resulting better oxidation process, lower combustion temperatures and higher $\mathrm{O}_{2}$ content in flue gasses. By nature of combustion process, this results in different $\mathrm{NO}_{x}$ emission production and process efficiency.

Although coal feeder load is significantly decreased with advanced control implementation, the primary air flow on burners have not been decreased accordingly. Primary air flow on some burners is even increased during some operating regimes.

This leads to conclusion that current thermal plant control utilise $1.67 \%$ more fuel than needed. By this, incomplete combustion and other unwanted combustion process effects regarding $\mathrm{NO}_{x}$ emissions and efficiency (higher temperature inside boiler, higher losses etc.) could occur. By different coal and primary air distribution this effects could be reduced or minimised. 

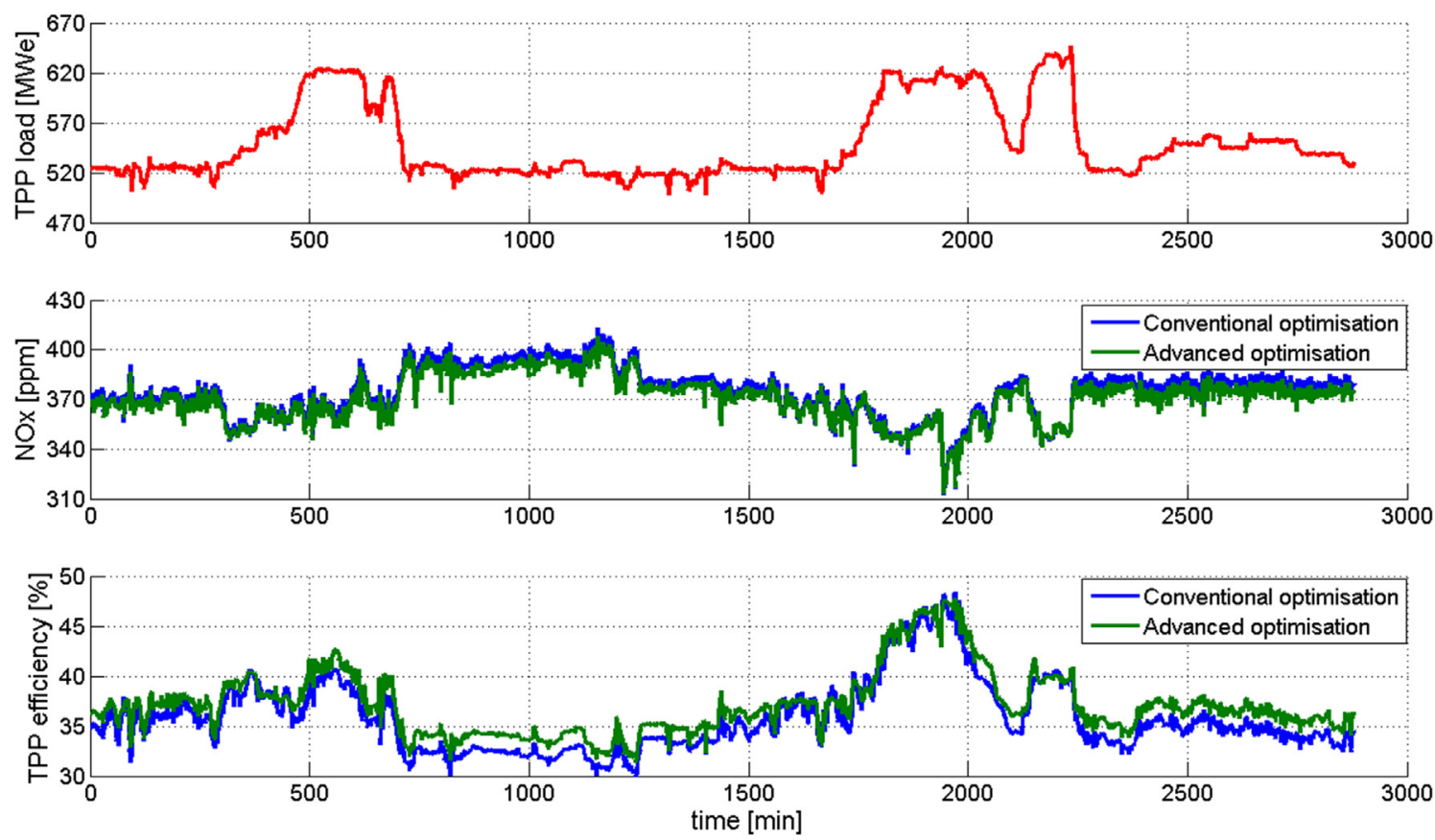

Fig. 8. Simulation results of estimated $\mathrm{NO}_{x}$ emissions and Unit efficiency after advanced controller implementation.

While changing primary air flow, advanced control simultaneously controls its distribution through secondary and tertiary air flow. By changing air distribution, combustion process changes.

Simulation results suggest that by introduction of advanced controller, distribution of secondary and tertiary air flow on burner is changed. On burner 4 secondary air flow is slightly increased while tertiary air flow is slightly decreased. Secondary and tertiary air flow on burner 5 are generally slightly decreased (Fig. 11).
As stated in Section 4, correction coefficients for advanced combustion control are set in range of $\pm 5 \%$. Coal feeder load on burner 3 is generally lower after implementation of advanced controller with correction coefficients. Correction coefficients for coal feeder load control are mostly set on $-5 \%$ (Fig. 12). In some cases, they are higher than zero which means that coal feeder load on burner 3 is higher (more coal is distributed to burner) after implementation of advanced controller. Correction coefficients for
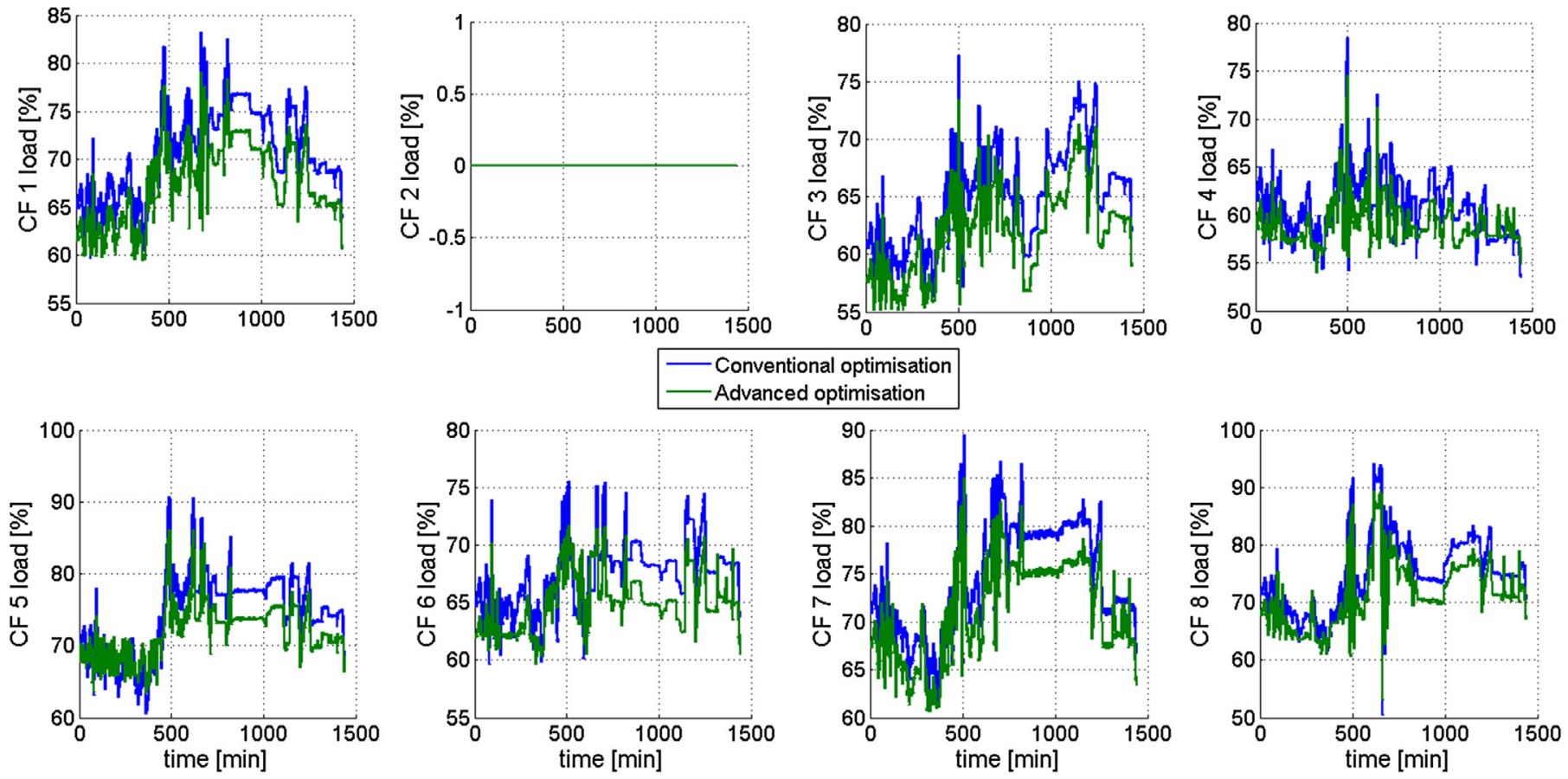

Fig. 9. Simulation results of coal feeder (CF) load before and after advanced controller implementation. 

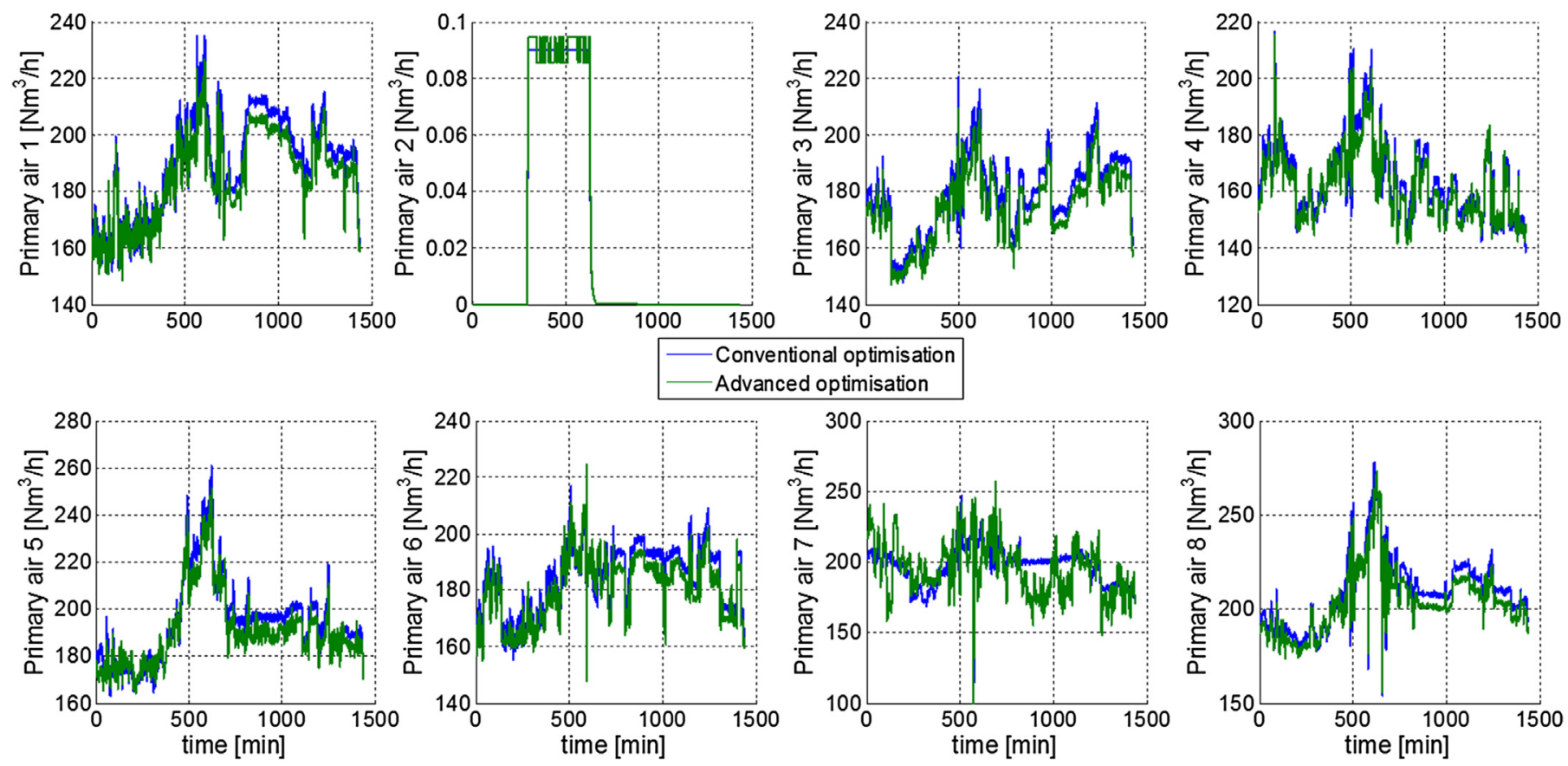

Fig. 10. Simulation results of primary air flow before and after advanced controller implementation.

secondary air on burner 3 are generally higher than zero and for tertiary air are generally lower than zero.

Most important parameters in $\mathrm{NO}_{x}$ formation process is fuel and air quantity. By decreasing fuel flow or increasing air flow, combustion temperature decreases which results in $\mathrm{NO}_{x}$ formation decrease. With higher air flow rate, the turbulence of combustion is also increased which results in better fuel-air mixing during combustion and reduces necessity for higher excess air. Higher quantities of air introduce additional nitrogen from air. Air is the main source of nitrogen in $\mathrm{NO}_{x}$ formation process during combustion. By changing air flow quantities and distribution in combustion process, $\mathrm{NO}_{x}$ formation rate is changed. $\mathrm{NO}_{x}$ formation reduction can be occurred in combustion zones where extreme high temperatures have been avoided [44].

By changing fuel and air flow, total process efficiency varies. As shown on Fig. 11, total (electric) Unit efficiency with current control is $35.76 \%$ through $48 \mathrm{~h}$ of operation. Simulation suggests that by advanced process control introduction, total Unit's efficiency rises.
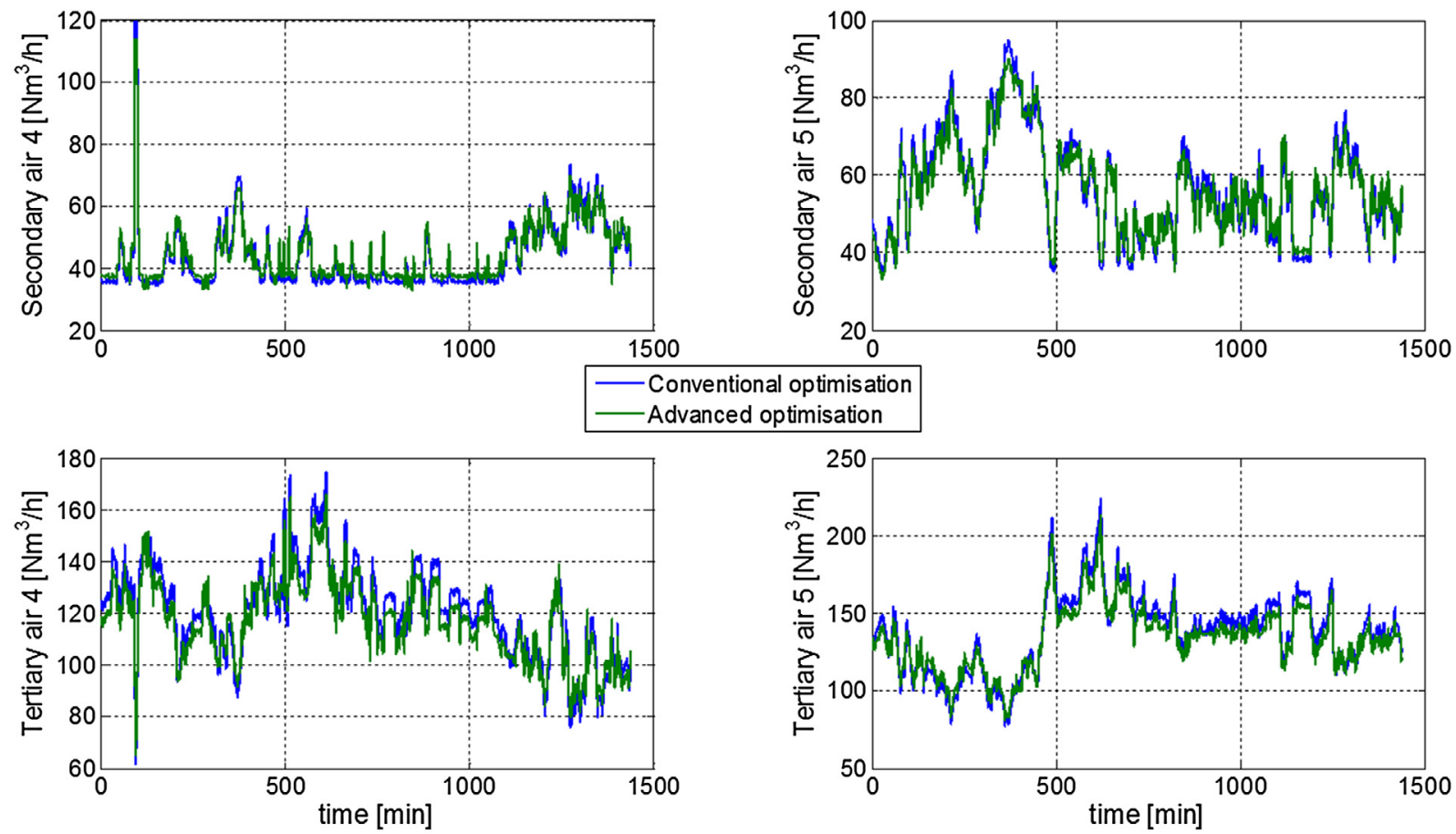

Conventional optimisation

Advanced optimisation

Fig. 11. Simulation results of secondary and tertiary air flow (right) on burners 4 and 5 before and after advanced controller implementation. 

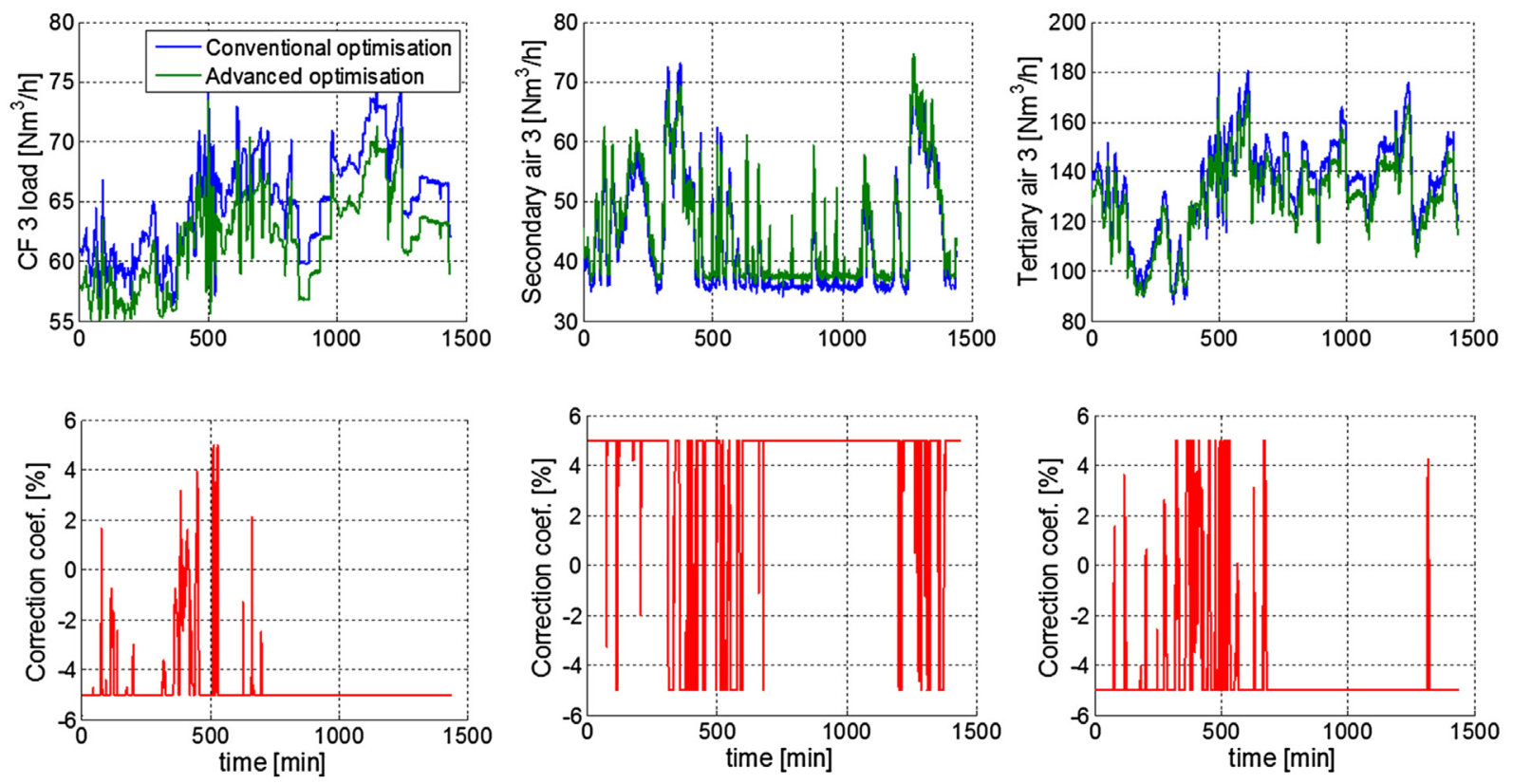

Fig. 12. Simulation results of advanced control operation on burner 3 .

Total Unit efficiency with advanced control is increased to $37.45 \%$. Total efficiency of coal fired thermal power plant during $48 \mathrm{~h}$ operation has risen for $1.39 \%$ in average.

Similar to Figs. 2-4, values of air flows and coal feeder loads in dependence of boiler thermal load have been calculated using ANFIS and control maps for advanced combustion control have been generated (Fig. 13).

The great effect on efficiency improvement is done by fuel flow reduction, especially on lower power plant loads. This could be result of poor power plant combustion process optimisation on lower loads. Poorly defined parameters for PI control on lower loads could also contribute to efficiency decrease.
Adding to much air to boiler could cause combustion temperature decrease and contribute to lower power plant efficiency. Simultaneously by combustion temperature decrease, $\mathrm{NO}_{x}$ formation rate is also decreasing. Therefore, it is necessary to find optimal fuel/air ratio. Air distribution affects more on $\mathrm{NO}_{x}$ formation decrease due to different combustion temperature profile.

Unit efficiency has been calculated regarding Unit electric output and total fuel consumption. Lower fuel heating value has been taken as constant (calculated regarding specifications given by coal provider). In the real power plant operation this will not be the case. Fuel with different composure (heating value, moisture composition etc.) is used for combustion process. Taking fuel with

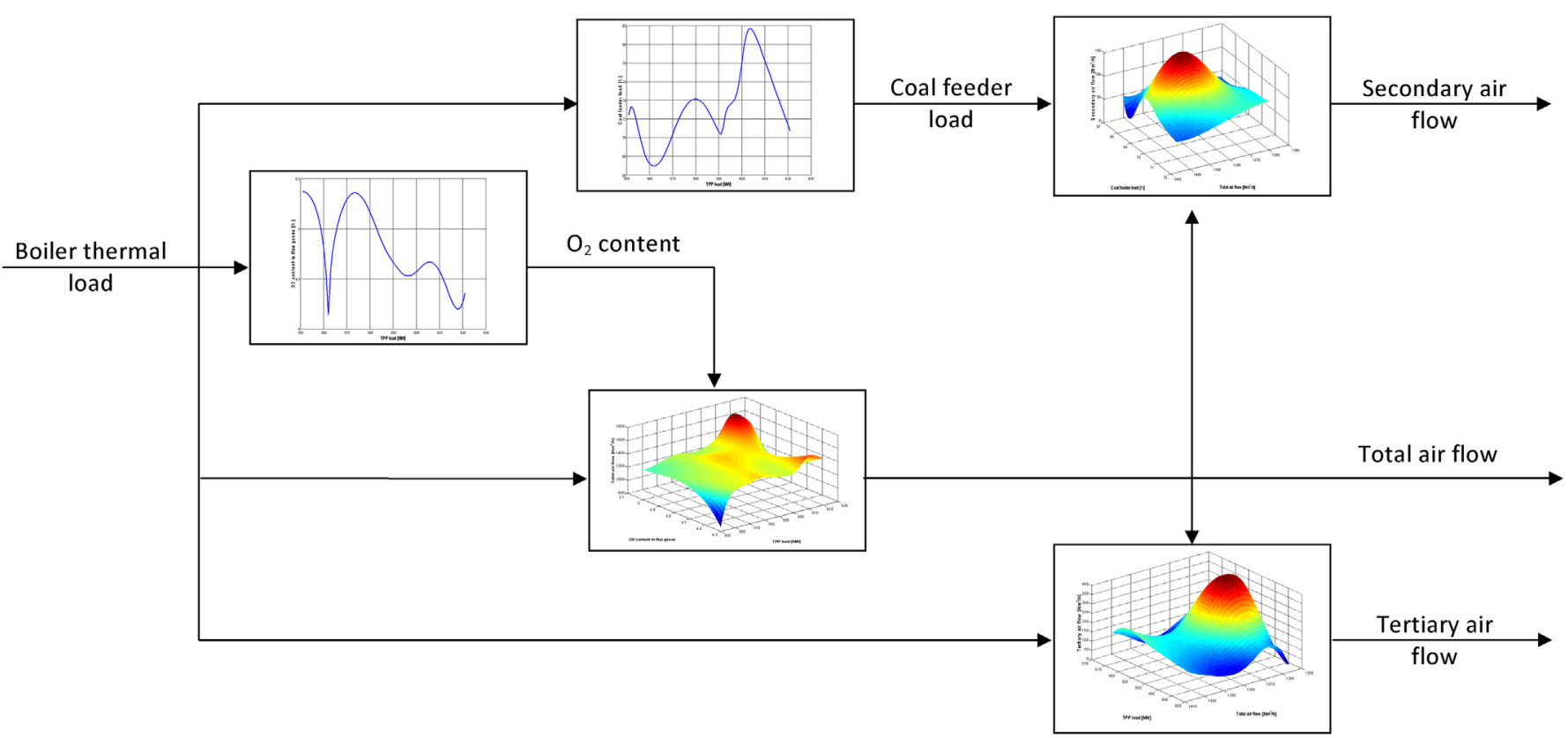

Fig. 13. Control maps for advanced air flow control. 
lower (or higher) heating value will lead to higher (or lower) fuel consumption in order to preserve the same Unit output. This phenomenon has not been taken into consideration due to lack of minute based fuel composition measurements. Other process parameters such as primary, secondary and tertiary air temperature and combustion temperature profiles should also be taken into consideration to make optimisation more precise. Thus, lack of detailed process parameters measurements (fuel heating value) for process parameter approximation and process optimisation could lead to misleading results and conclusions regarding Unit efficiency calculations.

\section{Conclusion}

This paper has analysed the possibilities of improvement of existing Western Balkan Countries coal fired thermal power plants performance by control systems modifications, particularly those based on artificial intelligence, in order to increase plant efficiency and to lower pollutants emissions. As one of primary measures, combustion control could be the most effective way to reduce emissions in existing thermal power plants. For the purpose of highly nonlinear coal combustion modelling and process parameter approximation, the adaptive neuro-fuzzy algorithms can be used. Data collected during power plant operation in correlation with process approximation model can be used for creating a selflearning controller that allows on-line plant process optimisation. During power plant operation, effects of self-learning controller on combustion process optimisation could be improved with additional data analysis. Simulation suggests that by different fuel and air distribution, $\mathrm{NO}_{x}$ formation could be decreased. Implementation of developed self-learning controller for combustion optimisation shows potential in terms of $\mathrm{NO}_{x}$ minimisation. Paper results should be analysed during real time thermal power plant operation in order to make further conclusions. Effects of additional process parameter data implementation in approximation and optimisation model as well as effects of controller learning process and "over learning" phenomenon on could be further investigated.

\section{Acknowledgements}

This paper has been created within WBalkICT - Supporting Common RTD actions in Western Balkan Countries for developing Low Cost and Low Risk ICT based solutions for TPPs Energy Efficiency increasing, SEE-ERA.NET plus project in cooperation among coordinator SC IPA SA - Romania and partners from University of Zagreb - Croatia and Institute of Nuclear Science "Vinča" from Serbia. Measurements are conducted on Thermal Power Plant “Nikola Tesla B", Obrenovac, Serbia.

\section{List of used abbreviations}

$\begin{array}{ll}\text { ACO } & \text { ant colony system } \\ \text { AIS } & \text { artificial intelligence systems } \\ \text { ANFIS } & \text { adaptive network-based fuzzy inference system } \\ \text { ANN } & \text { artificial neural networks } \\ \mathrm{CO} & \text { carbon monoxide } \\ \mathrm{CO}_{2} & \text { carbon dioxide } \\ \text { EA } & \text { Evolutional Algorithm } \\ \text { ERA.NET } & \text { European Research Area Net } \\ \text { EU } & \text { European Union } \\ \text { GA } & \text { genetic algorithm } \\ \text { LHV } & \text { lower heating value } \\ \text { MWe } & \text { Mega Watt electric } \\ \mathrm{NO}_{x} & \text { nitrate-oxides }\end{array}$
$\mathrm{O}_{2} \quad$ oxide
P unit output
PSC power system control
PSO particle swarm optimization
RTD Research and Technology Development

SC IPA SA rom. Societate comerciala pentru cercetare, proiectare si productie de echipamente si instalatii de automatizare

SCR selective catalytic reduction

SEE SouthEast European

$\mathrm{SO}_{x} \quad$ sulphur-oxides

TPP thermal power plant

USA United States of America

WBalkICT West Balkan Information and Communication Technology

\section{References}

[1] Barrett M. Atmospheric emissions from large point sources in Europe. Goteborg: Swedish NGO Secretariat on Acid Rain; 2004.

[2] International Energy Agency. The energy in Western Balkans. Paris: IEA Publications; 2008.

[3] Kaminski J. Technologies and costs of $\mathrm{SO}_{2}$-emissions reduction for the energy sector. Applied Energy 2003;75:165-72.

[4] Ren F, Li Z, Liu G, Chen Z, Zhu Q. Combustion and NOx emissions characteristics of a down-fired 660-MWe utility boiler retro-fitted with air-surrounding-fuel concept. Energy 2011;36:70-7.

[5] Zheng L, Shuijun Y, Minaggo Y. Monitoring $\mathrm{NO}_{x}$ emissions from coal-fired boilers using generalized regression neural network. In: Proceedings of international conference on bioinformatics and biomedical engineering. Shanghai, China: ICBBE; 2008.

[6] Lin W, Hong C, Cheng F. Fuzzy neural network output maximization control for sensorless wind energy conversion system. Energy 2010;35:592-601.

[7] Kim Y, Lewiss F, Dawson D. Intelligent optimal control of robotic manipulators using neural networks. Automatica 2000;36:1355-64.

[8] Artyomov E, Yadid-Pecht O. Modified high-order neural network for invariant pattern recognition. Pattern Recognition Letters 2005;26:843-51.

[9] Kljajić M, Gvozdenac D, Vukmirović S. Use of neural networks for modeling and predicting boiler's operating performance. Energy 2012;45:304-11.

[10] Yu S, Zhu K. A hybrid procedure for energy demand forecasting in China. Energy 2012;37:396-404.

[11] Ekonomou L. Greek long-term energy consumption prediction using artificial neural networks. Energy 2010;35:512-7.

[12] Almonacid F, Rus C, Perez-Higueras P, Hontoria L. Calculation of the energy provided by a PV generator. Comparative study: conventional methods vs. artificial neural networks. Energy 2011;36:375-84.

[13] Kiani Deh Kiani M, Ghobadian B, Tavakoli T, Nikbakht AM, Najafi G. Application of artificial neural networks for the prediction of performance and exhaust emissions in SI engine using ethanol- gasoline blends. Energy 2010;35:65-9.

[14] Hallner D, Hasenbring M. Classification of psychosocial risk factors (yellow flags) for the development of chronic low back and leg pain using artificial neural network. Neuroscience Letters 2004;361:151-4.

[15] Tu J. Advantages and disadvantages of using artificial neural networks versus logistic regression for predicting medical outcomes. Journal of Clinical Epidemiology 1996;49:1225-31.

[16] Palme T, Fast M. Application of artificial neural networks to the condition monitoring and diagnosis of a combined heat and power plant. Energy 2010;35:1114-20.

[17] Romeo L, Gareta R. Neural network for evaluating boiler behaviour. Applied Thermal Engineering 2006;26:1530-6.

[18] Kim I, Son J, Lee S, Prasad KD, Yarlgadda V. Optimal design of neural networks for control in robotic arc welding. Robotics and Computer-integrated Manufacturing 2004;20:57-63.

[19] Kusiak A, Zheng H. Optimization of wind turbine energy and power factor with an evolutionary computation algorithm. Energy 2010;35:1324-32.

[20] Rashidi MM, Galanis N, Nazari F, Basiri Parsa A, Shamekhi L. Parametric analysis and optimization of regenerative Clausius and organic Rankine cycles with two feedwater heaters using artificial bees colony and artificial neural network. Energy 2011;36:5728-40.

[21] Uncini A. Audio signal processing by neural networks. Neurocomputing 2003;55:593-625.

[22] Mundy P, Jarrold W. Infant joint attention, neural networks and social cognition. Neural Networks 2010;23:985-97.

[23] Rusinowski H, Stanek W. Neural modelling of steam boilers. Energy Conversion and Management 2007;48:2802-9.

[24] Rusinowski H, Stanek W. Hybrid model of steam boiler. Energy 2010;35: 1107-13.

[25] Liukkonen M, Heikkinen M, Hiltunen T, Halikka E, Kuivalainen R, Hiltunen Y. Artificial neural networks for analysis of process states in fluidized bed combustion. Energy 2011;36:339-47. 
[26] Kalogirou S. Applications of artificial neural-networks for energy systems. Applied Energy 2000;67:17-35.

[27] Kalogirou S. Artificial intelligence for the modeling and control of combustion processes: a review. Renewable and Sustainable Energy Reviews 2001;5: 373-401.

[28] Jakoubek P, Hofreiter M, Bouda L. Probabilistic approach to NO and CO emission modelling. In: Proceedings of the 12th international conference on automatic control, modelling \& simulation. Stevens Point, USA: WSEAS; 2010

[29] Zhou H, Cen K, Fan J. Modeling and optimization of the NOx emission characteristics of a tangentially fired boiler with artificial neural networks. Energy 2004;29:167-83.

[30] Zheng L, Zhou H, Cen K, Wang C. A comparative study of optimization algorithms for low NOx combustion modification at a coal-fired utility boiler. Expert Systems with Applications 2009;36:2780-93.

[31] Smrekar A, Assadi M, Fast M, Kustrin I, De S. Development of artificial neural network model for a coal-fired boiler using real plant data. Energy 2007;32: 2099-109.

[32] Suresh MVJJ, Reddy KS, Kolar AK. ANN-GA based optimization of a high ash coal-fired supercritical power plant. Applied Energy 2011;88:4867-73.

[33] Sacco WF, Pereira CMNA, Soares PPM, Schirru R. Genetic algorithms applied to turbine extraction optimization of a pressurized-water reactor. Applied Energy 2002;73:2177-222.

[34] Kusiak A, Li M, Tang F. Modeling and optimization of HVAC energy consumption. Applied Energy 2010;87:3092-102.

[35] Mikulandric R, Loncar D, Schneider DR, Cvetinovic D, Spiridon G. Improvement of environmental aspects of thermal power plant operation by advanced control concepts. Thermal Science 2012;16:759-72.

[36] Basu M. Fuel constrained economic emission load dispatch using Hopfield neural networks. Electric Power Systems Research 2002;63:51-7.

[37] Huan-Wen Tzeng HW, Jiann-Liang Chen JL. A neural-net approach for economic dispatch of Taiwan power system. In: Proceedings of the ICARCV second international conference on automation. Singapore: Robotics and Computer Vision; 1992.

[38] Kassem AM. Neural predictive controller of a two-area load frequency control for interconnected power system. Ain Shams Engineering Journal 2010;1:49-58.
[39] Deihimi A, Showkati H. Application of echo state networks in short-term electric load forecasting. Energy 2012;39:327-40.

[40] Lotufo AD, Lopes ML, Minussi C. Sensitivity analysis by neural networks applied to power systems transient stability. Electric Power Systems Research 2007;77:730-8.

[41] Cannas B, Celli G, Marchesi M, Pilo F. Neural networks for power system condition monitoring and protection. Neurocomputing 1998;23:111-23.

[42] Basheer I, Hajmeer M. Artificial neural networks: fundamentals, computing, design, and application. Journal of Microbiological Methods 2000;43:3-31.

[43] Mitrowski A. Bio-inspired online optimization for coal fired plant performance and emission improvement. In: Proceedings of the POWER-GEN Europe conference. Cologne, Germany: POWER-GEN; 2011

[44] Pitscheider K, Welfonder E. Model based online minimization of NOx-emission in power plants with pulverized coal combustion. In: Proceedings of the 13th Triennial World Congress. San Francisco, USA; 1996.

[45] Graus WHJ, Worrell E. Effects of $\mathrm{SO}_{2}$ and $\mathrm{NO} x$ control on energy-efficiency power generation. Energy Policy 2007;35:3898-908.

[46] Chandwani SG, Turoni F, Hlawnka A, Haug M, Schreiber M. Online combustion optimiser for thermal power plants. In: Proceedings of the POWER-GEN Europe conference. Cologne, Germany: POWER-GEN; 2011.

[47] Vargas PAM. Potentials and limits of flexible power plant operation. In: Proceedings of the POWERGEN Europe conference. Cologne, Germany: POWERGEN; 2011.

[48] Franco A, Diaz AR. The future challenges for "clean coal technologies": joining efficiency increase and pollutant emission control. Energy 2009;3:348-54.

[49] Tosun m, Dincer K, Baskaya S. Rule-based mamdani-type fuzzy modelling of thermal performance of multi-layer precast concrete panels used in residential buildings in Turkey. Expert Systems with Applications 2011;38:5553-60.

[50] Grauel A, Ludwig LA. Construction of differentiable membership functions. Fuzzy Sets and Systems 1999;101:219-25.

[51] Yu J, Wang S, Xi L. Evolving artificial neural networks using an improved PSO and DPSO. Neurocomputing 2008;71:1054-60.

[52] Nunnari G, Dorling S, Schlink U, Cawley G, Foxall R, Chatterton T. Modelling $\mathrm{SO}_{2}$ concentration at a point with statistical approaches. Environmental Modelling \& Software 2004;19:887-905. 